\title{
Association of gastric cancer with cytochrome P450 2C19 single-nucleotide polymorphisms in Koreans
}

\author{
Hyun-Ju Kim ${ }^{1}$, Hye-Jung Park ${ }^{1}$, Sang-Gyu Lee ${ }^{2}$, Hye-Suk Lee ${ }^{1}$, Won-Cheol Park ${ }^{3}$, Jeong-Joong Kim ${ }^{3}$, \\ Gyung-Jae $\mathrm{Oh}^{3}$ and Yun-Kyung Kim ${ }^{1,}$ \\ ${ }^{I}$ College of Pharmacy, Wonkwang University 344-2 Shinyong-dong, Iksan, Jeonbuk, 570-749 Republic of Korea; \\ ${ }^{2}$ College of Oriental Medicine, Wonkwang University 344-2 Shinyong-dong, Iksan, Jeonbuk, 570-749 Republic of \\ Korea: ${ }^{3}$ College of Medicine, Wonkwang University, 344-2 Shinyong-dong, Iksan, Jeonbuk, 570-749 Republic of Korea
}

\begin{abstract}
SUMMARY
Cytochrome P450 2C19 (CYP2C19) is a clinically important enzyme involved in the metabolism of therapeutic drugs, including (S)-mephenytoin, omeprazole, proguanil, and diazepam. Individuals are characterized as either extensive metabolizers (EM) or poor metabolizers (PM) on the basis of CYP2C19 enzyme activity. The PM phenotype occurs in $2-5 \%$ of Caucasians, but in $18-23 \%$ of Asians. To clarify the association between CYP2C19 polymorphisms and gastric cancer in Koreans, we investigated CYP2C19 genotypes (CYP2C19*1, *2, and *3) in 109 patients with gastric cancer and 211 controls. Normal (CYP2C19*1) and defective alleles were detected with polymerase chain reaction/restriction enzyme analysis. CYP2C19 has three hereditary genotypes: homozygous EM, with high enzymatic activity; heterozygous EM, with moderate enzymatic activity; and PM, with no enzyme activity. We found that CYP2C19 heterozygous EM is more closely associated with gastric cancer than is homozygous EM. Because the CYP2C19 genotype varies in Koreans, a genotyping test is desirable to prevent gastropathy recurrence in patients before their doses of omeprazole are reduced during maintenance therapy.
\end{abstract}

Key words: CYP2C19; Korean; Gastric cancer; Genotypes; SNP

\section{INTRODUCTION}

Gastric cancer is one of the most common cancers in the world and is the leading cause of death in Korea. Cytochrome P450 2C19 (CYP2C19) is a clinically important enzyme involved in the metabolism of drugs such as (S)-mephenytoin, omeprazole, proguanil, and diazepam (Xie et al., 2001). CYP2C19 also plays a crucial role in either the detoxification or inactivation of potential carcinogens, and in the bioactivation of some

*Correspondence: Yun-Kyung Kim, College of Pharmacy, Wonkwang University, 344-2 Shinyong-dong, Iksan, Jeonbuk, 570-749 Republic of Korea. Tel: +820638506803; Fax: +820638506803; E-mail: hestia@wku.ac.kr environmental procarcinogens to reactive DNAbinding metabolites, such as nitrosamine (Kamataki et al., 2002; Xing et al., 2003; Agundez et al., 2004). Therefore, CYP2C19 polymorphisms are considered one of the factors associated with interindividual differences in susceptibility to certain forms of cancer, as is true for other CYP enzymes (Tsuneoka et al., 1996; Yokose et al., 1998; Gao et al., 2002; Shi et al., 2004; Suzuki et al., 2004; Sugimoto et al., 2005). Several recent reports have related CYP2C19 polymorphisms and susceptibility to various cancers, including lung cancer (Tsuneoka et al., 1996; Shi et al., 2004), hepatocellular carcinoma (Chau et al., 2000), esophageal cancer, and gastric cancer (Shi et al., 2004) 
There are also interethnic differences in the frequencies of CYP2C19 genotypes. In eastern Asian populations, such as the Japanese, Chinese, and Koreans, the frequencies of homozygous extensive metabolizers (EMs), heterozygous EMs, and poor metabolizers (PMs) are approximately $30-40 \%, 4-50 \%$, and $14-22 \%$, respectively, whereas in American and European Caucasians, they are approximately $70-75 \%, 20-25 \%$, and $2-5 \%$, respectively (Ishizaki et al., 1994; Xiao et al., 1997; Xie et al., 1999).

If CYP2C19 activity is a risk factor for developing gastric cancer, the higher frequency of the CYP2C19 PM genotypes in the Korean population might explain their higher incidence of gastric cancer compared with that of Caucasians. Therefore, the aim of this study was to evaluate the relationship between CYP2C19 polymorphisms and gastric cancer using CYP2C19 genotyping in Korean gastric cancer patients and healthy volunteers.

\section{METHODS}

\section{Subjects}

Gastric cancer patients $(n=109)$ underwent surgical or endoscopic mucosal resection between August 2003 and February 2005, at Wonkwang University Hospital, Iksan, Chonbuk, Republic of Korea. and the diagnosis of gastric adenocarcinoma was confirmed pathologically. They had a mean age $( \pm$ S.D.) of $60.1 \pm 12.0$ years. The control group consisted of 211 healthy volunteers, who were deemed to be free of malignancy by their physicians. They had a mean age of $25.5 \pm 5.4$ years. All patients and control subjects gave their written informed consent prior to their enrolment in this study. The Institutional Review Boards of Wonkwang University Hospital approved this study.

\section{Blood sampling and DNA extraction}

Blood samples ( $3 \mathrm{ml}$ collected by vein puncture into EDTA) were obtained from all subjects. Immediately after its collection, the whole blood was stored at $-20^{\circ} \mathrm{C}$ until use. The inorganic procedure for DNA extraction was based on that of Miller et al. (1988). The concentration of the DNA was estimated by absorbance at $260 \mathrm{~nm}$.

\section{Primer design}

We designed specific primers for exon 5 (CYP2C19*2) and exon 4 (CYP2C19*3) according to the base sequence of the CYP2C19 gene at intron 5-intron 6 and intron 4-intron 5, respectively, as previously described by de Morais et al. (1994), with minor modifications. For exon $5\left(\mathrm{CYP} 2 \mathrm{C} 19^{*} 2\right)$, the forward primer was 5'-AATTACAACCAGAGCTTGGC-3' and the reverse primer was 5'-TATCACTTTCCATAAAAGCAA-3'; for exon 4 (CYP2C19*3), the forward primer was 5'-TATTATTATCTGTTAACTAATATGA$3^{\prime}$ and the reverse primer was 5-ACTTCAGGGCTTGGTCAATA-3'.

\section{Polymerase chain reaction-restriction fragment length polymorphism (PCR-RFLP) analysis} To detect the CYP2C19*2 and CYP2C19*3 mutant alleles, genomic DNA (200 ng) was amplified in a PCR reaction that contained $10 \times$ buffer, $200 \mu \mathrm{mol}$ of dNTPs (dATP, dCTP, dGTP, and dTTP), $1.5 \mathrm{mM}$ $\mathrm{MgCl}_{2}, 0.5 \mathrm{mmol}$ of PCR primers, and 2.5 units of AmpliTaq DNA polymerase. The amplification conditions were 35 cycles of denaturation at $94^{\circ} \mathrm{C}$ for $30 \mathrm{~s}$, annealing (at $55^{\circ} \mathrm{C}$ for exon 5 and $49.7^{\circ} \mathrm{C}$ for exon 4) for $30 \mathrm{~s}$ and extension at $72^{\circ} \mathrm{C}$ for $45 \mathrm{~s}$. An initial denaturation step at $94^{\circ} \mathrm{C}$ for $5 \mathrm{~min}$ and a final extension step at $72^{\circ} \mathrm{C}$ for $5 \mathrm{~min}$ were also included. The PCR products of CYP2C19*2 and CYP2C19*3 were digested with SmaI and BamHI enzymes, respectively. Restriction enzyme cleavage was conducted (for $\mathrm{CYP} 2 \mathrm{C} 19^{*} 2$ at $25^{\circ} \mathrm{C}$; for $\mathrm{CYP} 2 \mathrm{C} 19^{*} 3$ at $37^{\circ} \mathrm{C}$ ) for $8 \mathrm{~h}$ after the addition of 10 units of SmaI and BamHI. The digested PCR products were analyzed on 3\% agarose gels, after staining with ethidium bromide.

\section{Data analysis}

Differences in the CYP2C19 genotype frequencies 
in the control and gastric cancer groups were determined using the $\chi^{2}$ test. The effects of the CYP2C19 genotypes on the risk of gastric cancer development were expressed as odds ratios (OR) adjusted for age and sex, with $95 \%$ confidence intervals (CI). All $P$ values were two sided, and $P$ values of $<0.05$ were considered statistically significant (SPSS 10.0; SPSS, Chicago, IL, USA).

\section{CYP2C19 genotyping}

Restriction analysis of the wild type appeared as two bands of digestion products (of 120 and $49 \mathrm{bp}$ for CYP2C19*2, and 233 and 96 bp for CYP2C19*3). Conversely, the homozygous mutated type appeared as a single band of undigested product (169 bp for CYP2C19*2, and 329 bp for CYP2C19*3). If all products (three bands) appeared on the gel, the subject was heterozygous.

CYP2C19 genotypes were classified into three groups: the homozygous EM $\left({ }^{*} 1 /{ }^{*} 1\right)$, heterozygous $\operatorname{EM}\left({ }^{*} 1 /{ }^{*} 2\right.$ or $\left.{ }^{*} 1 /{ }^{*} 3\right)$, and PM $\left(* 2 / * 2, * 3 / * 3\right.$, or $\left.{ }^{*} 2 / * 3\right)$.

\section{RESULTS}

In the wild-type gene, cleavage of the PCR products yielded fragments of 120 and $49 \mathrm{bp}$ for CYP2C19*2, and 233 and $96 \mathrm{bp}$ for CYP2C19*3. With individuals homozygous for CYP2C19*2, the SmaI site in exon 5 is destroyed and the 169-bp fragment is not cut, whereas in CYP2C19*3, the BamHI site in exon 4 is destroyed and the 329-bp fragment is not cut. With heterozygous individuals, all three bands $(49,120$, and $169 \mathrm{bp}$ for CYP2C19*2, and 96, 233, and $329 \mathrm{bp}$ for CYP2C19*3) are evident. PCR products from
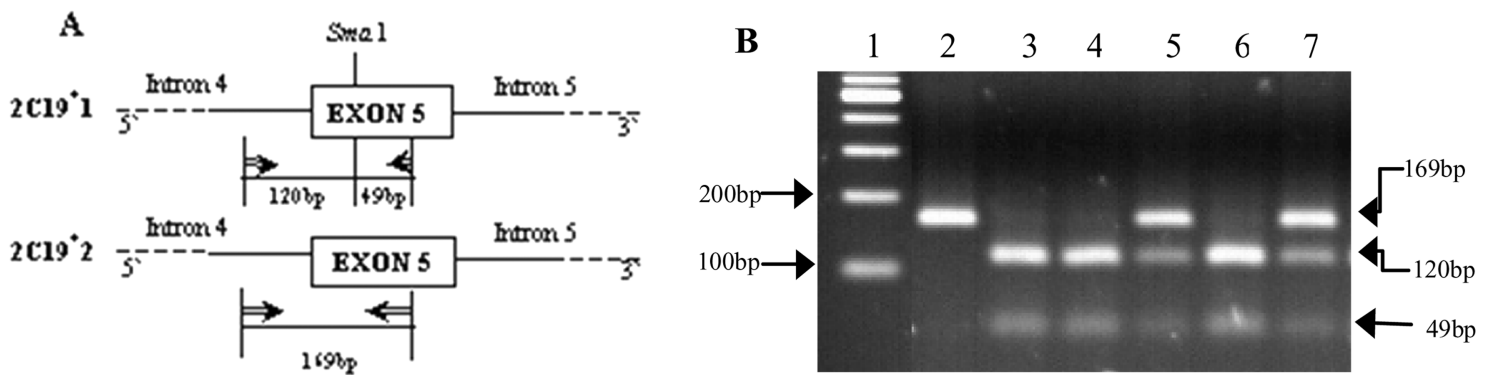

Fig. 1. PCR-based diagnostic test for CYP2C19*2 mutation. A, Strategy used to genotype genomic DNA from human blood, using PCR amplification of exon 5 followed by SmaI digestion (CYP2C19*2). B, Gel electrophoresis photograph showing the analysis of CYP2C19*2. Lane 1 is a 100-bp size marker. Lane 2 is homozygous $\left(\mathrm{CYP} 2 \mathrm{C} 19^{*} 2{ }^{*} 2\right)$, lanes 3,4 , and 6 are wild type $\left(\mathrm{CYP} 2 \mathrm{C} 19^{*} 1{ }^{*} 1\right)$, and lanes 5 and 7 are heterozygous $\left(\mathrm{CYP} 2 \mathrm{C} 19^{*} 1 /{ }^{*} 2\right)$.

Table 1. Frequencies of CYP2C19 genotypes in controls and patients with gastric cancer

\begin{tabular}{cccc}
\hline CYP2C19 genotype & Gastric cancer no. (\%) & Control no. $(\%)$ & P \\
\hline $\begin{array}{c}\text { Homozygous EM } \\
{ }^{*} 1 /{ }^{*} 1,{ }^{*} 1 /{ }^{*} 1\end{array}$ & $36(33.0)$ & & \\
\hline Heterozygous EM & & & \\
${ }^{*} 1 /{ }^{*} 2,{ }^{*} 1 /{ }^{*} 1$ & $44(40.4)$ & $61(28.9)$ & \\
${ }^{*} 1 /{ }^{*} 1, * 1 /{ }^{*} 3$ & $13(11.9)$ & $24(11.4)$ & 0.109 \\
Total & $57(52.3)$ & $85(40.3)$ & \\
\hline PM & $7(6.4)$ & $12(5.7)$ & \\
${ }^{*} 1 /{ }^{*} 2,{ }^{*} 1 /{ }^{*} 3$ & $9(8.3)$ & $20(9.5)$ & \\
${ }^{*} 2 /{ }^{*} 2,{ }^{*} 1 /{ }^{*} 1$ & $0(0.0)$ & $2(0.9)$ & \\
${ }^{*} 1 /{ }^{*} 1, * 3 /{ }^{*} 3$ & $16(14.7)$ & $34(16.1)$ & \\
Total & & & \\
\hline
\end{tabular}

The data were analyzed with the $\chi^{2}$ test. 

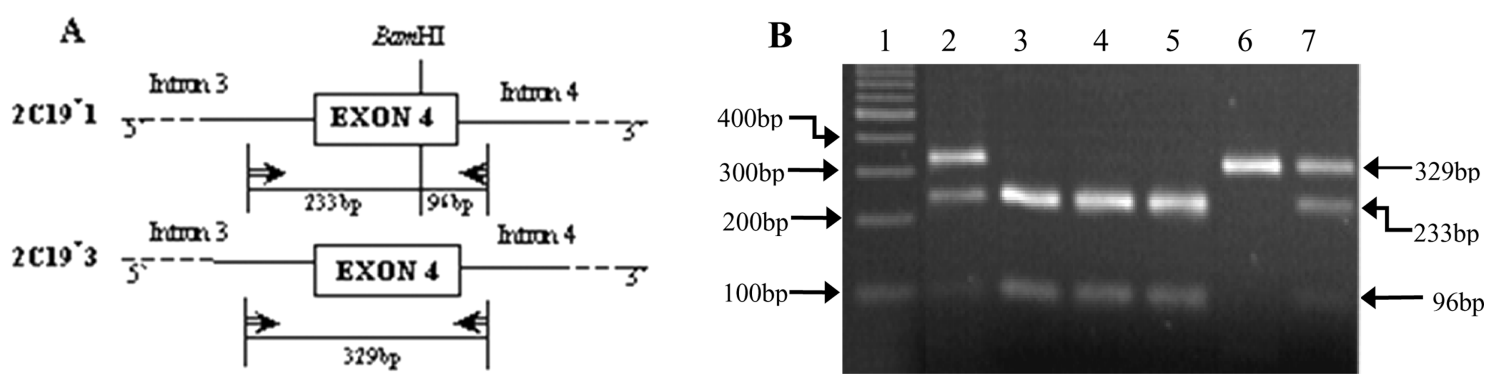

Fig. 2. PCR-based diagnostic test for the CYP2C19*3 mutation. A, Strategy used to genotype genomic DNA from human blood, using PCR amplification of exon 4 followed by BamHI digestion (CYP2C19*3). B, Gel electrophoresis photograph showing the analysis of CYP2C19*3. Lane 1 is a 100-bp size marker. Lanes 2 and 7 are heterozygous (CYP2C19*1/*3), lanes 3,4 , and 5 are wild type (CYP2C19*1/*1), and lane 6 is homozygous $\left(\mathrm{CYP} 2 \mathrm{C} 19 * 3 /{ }^{*} 3\right)$.

Table 2. Frequencies of CYP2C19 homozygous EM and heterozygous EM genotypes in controls and patients with gastric cancer

\begin{tabular}{|c|c|c|c|c|}
\hline CYP2C19 genotype & Gastric cancer no. (\%) & Control no. (\%) & $\mathrm{P}$ & OR $(95 \% \mathrm{CI})$ \\
\hline $\begin{array}{c}\text { Homozygous EM } \\
{ }^{*} 1 /{ }^{*} 1,{ }^{*} 1 /{ }^{*} 1\end{array}$ & $36(38.7)$ & $92(52.0)$ & \multirow[b]{2}{*}{0.038} & \multirow[b]{2}{*}{$\begin{array}{c}0.584 \\
(0.35-0.97)\end{array}$} \\
\hline $\begin{array}{c}\text { Heterozygous EM } \\
{ }^{*} 1 /{ }^{*} 2,{ }^{*} 1 /{ }^{*} 1 \\
{ }^{*} 1 /{ }^{*} 1,{ }^{*} 1 /{ }^{*} 3\end{array}$ & $57(61.3)$ & $85(48.0)$ & & \\
\hline
\end{tabular}

The data were analyzed with the $\chi^{2}$ test.

DNA individuals with the wild-type allele(s) were cleaved by the restriction enzyme, whereas those from homozygous individuals with the mutations $* 2 /{ }^{*} 2$ or $* 3 / * 3$ lacked the SmaI or BamHI site, respectively, and showed a single band (Figs. 1 and 2).

The frequencies of the homozygous EM, heterozygous EM, and PM CYP2C19 genotypes were $43.6 \%, 40.3 \%$, and $16.1 \%$, respectively, in the control group and $33.0 \%, 52.3 \%$, and $14.7 \%$, respectively, in the gastric cancer group. Although there was no significant difference between the total PM frequencies of the gastric cancer group and the control group, the frequency of the homozygous EM genotype was $52.0 \%$ in the total control group and only $38.7 \%$ in the gastric cancer group. However, the frequency of the heterozygous EM genotype was $48.0 \%$ in the total control group and considerably higher in the gastric cancer group, at $61.3 \%$ (OR, 0.584; 95\% CI, 0.35 - 0.97).

\section{DISCUSSION}

Cytochrome P450s are the main drug-metabolizing enzymes in the human body, and always participate in the metabolism of carcinogens or procarcinogens. Some cytochrome P450s are involved in the activation of procarcinogens and some may take part in the inactivation of carcinogens. Several studies of CYP2C19 polymorphisms and their association with carcinogenesis have shown contradictory results (Wadelius et al., 1999; Roddam et al., 2000; Sachse et al., 2002). In one example, there was no relationship between prostate cancer and CYP2C19 polymorphisms. However, Klose et al. (1999) have reported that CYP2C19 is only expressed in the liver and duodenum. How it functions differently in different organs has not yet been clarified. This implies that different types of cancers may have different oncological mechanisms. 
Among the polymorphisms of CYP2C19, the mutations $\mathrm{CYP} 2 \mathrm{C} 19^{*} 2$ and $\mathrm{CYP} 2 \mathrm{C} 19^{*} 3$ are very important. In particular, the CYP2C19*3 allele is not observed in Caucasians, reflecting interethnic differences. In this study, CYP2C19*2 and CYP2C19*3 were detected in Koreans. However, the polymorphic distribution of the CYP2C19 gene does not differ in Korean gastric cancer patients and healthy Korean subjects.

However, CYP2C19 can be classified by enzyme activity and genotype into three hereditary phenotypes: homozygous EM, with higher enzymatic activity; heterozygous EM, with moderate enzymatic activity; and PM, with no enzymatic activity.

We found that the incidence of PMs in Koreans according to genotype is up to $16 \%$, higher than that of Caucasians, which is reported to be $2 \%-5 \%$ (Xiao et al., 1997; Xie et al., 1999). Furthermore, in this study, the heterozygous CYP2C19 EM genotype showed a higher frequency in gastric cancer patients than did the homozygous CYP2C19 EM genotype.

We can infer that PMs, caused by mutation of the CYP2C19 gene in gastric cancer patients, is associated with a higher incidence of gastric cancer in Koreans. This should be verified by data drawn from more samples. The contribution of CYP2C19 polymorphisms to the mechanism of gastric cancer in patients remains to be determined. The clinical usefulness of CYP2C19 genotyping in the prevention and screening of gastric cancer must also be investigated further.

This finding could be important for the clinical efficacy and toxicity of many therapeutic agents that are metabolized by CYP2C19, such as omeprazole. Thus, phenotype-genotype correlations, using a healthy population as the reference standard, may be a means by which to monitor changes in drug-metabolizing enzyme activities in diseases such as cancer.

\section{ACKNOWLEDGEMENTS}

This paper was supported by Wonkwang University, 2005.

\section{REFERENCES}

Agundez JA. (2004) Cytochrome P450 gene polymorphism and cancer. Curr. Drug Metab. 5, 211-224.

Chau TK, Marakami S, Kawai B, Nasu K, Kubota T, Ohnishi A. (2000) Genotype analysis of the CYP2C19 gene in HCV-seropositive patients with cirrhosis and hepatocellular carcinoma. Life Sci. 67, 1719-1724.

De Morais SM, Wilkinson GR, Blaisdell J, Meyer UA, Nakamura K, Goldstein JA. (1994) Identification of a new genetic defect responsible for the polymorphism of (S)-mephenytoin metabolism in Japanese. Mol. Pharmacol. 46, 594-598.

De Morais SM, Wilkinson GR, Blaisdell J, Nakamura K, Meyer UA, Goldstein JA. (1994) The major genetic defect responsible for the polymorphism of S-mephenytoin metabolism in humans. J. Biol. Chem. 269, 15419-15422.

Gao C, Takezaki T, Wu J, Li Z, Wang J, Ding J, Liu Y, $\mathrm{Hu} X$, Xu T, Tajima K, Sugimura H. (2002) Interaction between cytochrome P-450 2E1 polymorphisms and environmental factors with risk of esophageal and stomach cancers in Chinese. Cancer Epidemiol. Biomarkers Prev. 11, 29-34.

Ishizaki T, Sohn DR, Kobayashi K, Chiba K, Lee KH, Shin SG, Andersson T, Regårdh CG, Lou YC, Zhang Y, Dahl ML, Bertilsson L. (1994) Interethnic differences in omeprazole metabolism in the two S-mephenytoin hydroxylation phenotypes studied in Caucasians and Orientals. Ther. Drug Monit. 16, 21-215.

Kamataki T, Fujita K, Nakayama K, Yamazaki Y, Miyamoto M, Ariyoshi N. (2002) Role of human cytochrome P450 (CYP) in the metabolic activation of nitrosamine derivatives: application of genetically engineered Salmonella expressing human CYP. Drug Metab. Rev. 34, 667-676.

Klose TS, Blaisdell JA, Goldstein JA (1999) Gene structure of $C Y P 2 C 8$ and extrahepatic distribution of the human CYP2Cs. J. Biochem.Mol. Toxicol. 13, 289-295.

Roddam PL, Rollinson S, Kane E, Roman E, Moorman A, Cartwright R, Morgan GJ. (2000) Poor metabolizers at the cytochrome P450 2D6 and 2C19 loci are at increased risk of developing adult acute leukaemia. Pharmacogenetics 10, 605-615. 
Sachse C, Smith G, Wilkie MJ, Barrett JH, Waxman R, Sullivan F, Forman D, Bishop DT, Wolf CR. (2002) A pharmacogenetic study to investigate the role of dietary carcinogens in the etiology of colorectal cancer. Carcinogenesis 23, 1839-1849.

Shi WX, Chen SQ. (2004) Frequencies of poor metabolizers of cytochrome P450 2C19 in esophagus cancer, stomach cancer, lung cancer and bladder cancer in Chinese population. World J. Gastroenterol. 10, 1961-1963.

Sugimoto M, Furuta T, Shirai N, Nakamura A, Kajimura M, Sugimura H, Hishida A, Ishizaki T. (2005) Poor metabolizer genotype status of CYP2C19 is a risk factor for developing gastric cancer in Japanese patients with Helicobacter pylori infection. Aliment. Pharmacol. Ther. 22, 1033-1040.

Suzuki S, Muroishi Y, Nakanishi I, Oda Y. (2004) Relationship between genetic polymorphisms of drug-metabolizing enzymes (CYP1A1, CYP2E1, GSTM1, and NAT2), drinking habits, histological subtypes, and $p 53$ gene point mutations in Japanese patients with gastric cancer. J. Gastroenterol. 39, 220230.

Tsuneoka Y, Fukushima K, Matsuo Y, Ichikawa Y, Watanabe Y. (1996) Genotype analysis of the CYP2C19 gene in the Japanese population. Life Sci. 59, 17111715.
Wadelius M, Autrup JL, Stubbins MJ, Andersson SO, Johansson JE, Wadelius C, Wolf CR, Autrup H, Rane A. (1999) Polymorphisms in NAT2, CYP2D6, CYP2C19 and GSTP1 and their association with prostate cancer. Pharmacogenetics 9, 333-340.

Xiao ZS, Goldstein JA, Xie HG, Blaisdell J, Wang W, Jiang CH, Yan FX, He N, Huang SL, Xu ZH, Zhou $\mathrm{HH}$. (1997) Differences in the incidence of the CYP2C19 polymorphism affecting the $S$-mephenytoin phenotype in Chinese Han and Bai populations and identification of a new rare CYP2C19 mutant allele. J. Pharmacol. Exp. Ther. 281, 604-609.

Xie HG, Kim RB, Wood AJ, Stein CM. (2001) Molecular basis of ethnic differences in drug disposition and response. Annu. Rev. Pharmacol. Toxicol. 41, 815-850.

Xie HG, Kim RB, Stein CM, Wilkinson GR, Wood AJ. (1999) Genetic polymorphism of (S)-mephenytoin $4 \$$-hydroxylation in populations of African descent. Br. J. Clin Pharmacol. 48, 402-408.

Xing D, Tan W, Lin D. (2003) Genetic polymorphisms and susceptibility to esophageal cancer among Chinese population. Oncol. Rep. 10, 1615-1623.

Yokose T, Doy M, Kakiki M, Horie T, Matsuzaki Y, Mukai K. (1998) Expression of cytochrome P450 3A4 in foveolar epithelium with intestinal metaplasia of the human stomach. Jpn. J. Cancer Res. 89, 1028-1032. 